\title{
Neuroanatomy of a neurobehavioral disturbance in the left anterior thalamic infarction
}

\author{
Yoshiyuki Nishio, ${ }^{1}$ Mamoru Hashimoto, ${ }^{2}$ Kazunari Ishii, ${ }^{3}$ Etsuro Mori ${ }^{1}$
}

${ }^{1}$ Department of Behavioral Neurology and Cognitive Neuroscience, Tohoku University, Sendai, Japan ${ }^{2}$ Department of Psychiatry and Neuropathobiology, Kumamoto University, Kumamoto, Japan ${ }^{3}$ Department of Radiology, Kinki University, Sayama, Japan

\section{Correspondence to}

Dr Yoshiyuki Nishio, Department of Behavioral Neurology and Cognitive Neuroscience, Tohoku University Graduate School of Medicine; 2-1, Seiryo-machi, Aoba-ku, Sendai 980-8575, Japan;

nishiou@med.tohoku.ac.jp

Received 29 November 2010 Revised 15 February 2011 Accepted 8 March 2011 Published Online First 21 April 2011

\section{(2) UNLOCKA}

This paper is freely available online under the BMJ Journals unlocked scheme, see http:// jnnp.bmj.com/site/about/ unlocked.xhtml

\section{ABSTRACT}

Background and purpose Cognitive and behavioural symptoms represent primary clinical manifestations of anterior thalamic infarcts (ATIS) in the tuberothalamic artery territory. The aim of the study is to understand the pathomechanism of cognitive and behavioural disturbances in left ATI (LATI).

Methods 6 patients with isolated LATIs were investigated using neuropsychological assessments, MRI stereotactic lesion localisation and positron emission tomography.

Results The patients were characterised clinically by verbal memory impairment, language disturbances dominated by anomia and word-finding difficulty and apathy. The ventral anterior nucleus (VA) proper, magnocellular VA (VAmc), ventral lateral anterior nucleus (VLa), ventral lateral posterior nucleus (VLp) and mammillothalamic tract were involved in all patients. Compared with healthy controls, the regional cerebral blood flow was lower in the thalamus, the dorsolateral, medial and orbital frontal lobes, the anterior temporal lobe, the inferior parietal lobule and the occipital lobe of the left hemisphere.

Conclusions The authors propose that the Papez circuit disruption at the mammillothalamic tract and possibly thalamomedial temporal disconnection at the VA region is responsible for memory impairment and that the thalamo-anterior temporal disconnection is associated with language disturbance in LATI, respectively.

\section{INTRODUCTION}

Clinical observations have documented that the thalamus participates in a great variety of cognitive functions and mental activities, including memory, language, perception and emotion. ${ }^{1-3}$ However, the precise functional attributes of the individual thalamic nuclei and fibre systems remain to be elucidated. Clinicoanatomical investigations of thalamic infarctions, in which only subsets of thalamic structures are involved, have been one of the best ways to study the functional anatomy of the human thalamus. ${ }^{3}$ The inference of the function of individual thalamic structures on the basis of their anatomical connectivity with other brain regions has also played an important role. Here we highlight the left anterior thalamic infarction (LATI) resulting from occlusion of the left tuberothalamic artery, in which cognitive and behavioural symptoms represent primary clinical manifestations. ${ }^{3}$ Using neuropsychological evaluations, MRI stereotactic lesion localisation ${ }^{4}{ }^{5}$ and positron emission tomography (PET), we attempted to delineate neurobehavioral and neuroanatomical profiles of LATI.

\section{METHODS}

Subjects

We recruited six right-handed patients (mean age, $76 \pm 7.4$ years; two women; mean years of education, 9.2 \pm 2.9 ) with a subacute phase of isolated LATI. They were consecutive patients admitted to the Hyogo Institute for Aging Brain and Cognitive Disorders (HI-ABCD), a research-oriented dementia clinic, from 1993 to 2001. All of them presented to the institute with sudden onset of cognitive or behavioural problems, such as forgetfulness, loss of spontaneity and dysnomia. Duration between onset of symptoms and start of examination ranged from 1 to 4 weeks (mean, $3 \pm 1.3$ weeks). Their past medical history included hypertension, diabetes mellitus and rheumatoid arthritis. The inclusion criteria were as follows: (1) sudden onset of symptoms; (2) presence of circumscribed infarction in the anterior portion of the thalamus with a lack of lesions elsewhere on MRI; (3) no severe stenosis or occlusion of the major cerebral arteries on $M R$ angiography; (4) no history of other neurological and psychiatric diseases and (5) no history of premorbid cognitive impairment or behavioural abnormalities. The clinical diagnosis was made based on an examination by behavioural neurologists and psychiatrists and compared with MRI findings. All procedures used in this study were approved by the ethics committee of the HI-ABCD Written informed consents were obtained from both patients and their relatives or from the control subjects.

\section{Neuropsychology and behaviour}

Neuropsychological assessments were performed within 2 weeks before and after neuroimaging investigations. The batteries and tests used in the study comprised the Mini Mental State Examination, ${ }^{6}$ the Wechsler Adult Intelligence Scale-Revised (WAIS-R), ${ }^{7}$ the Wechsler Memory Scale-Revised (WMS-R), ${ }^{8}$ the Western Aphasia Battery, ${ }^{9} 100$-word object naming, ${ }^{10}$ verbal fluency (animals/initial letter), ${ }^{11}$ Raven's Coloured Progressive Matrices, ${ }^{12}$ the Weigl's Colour-Form Sorting Test $^{13}$ and Luria's executive/motor performance tests (fist-edge-palm test, 2-1 tapping test and alternative pattern drawing). ${ }^{14}$ These tests represent the domains of general intelligence, anterograde episodic memory, language/semantic knowledge, perceptual organisation/construction and executive function (concept formation, psychomotor speed and executive/motor control). Retrograde episodic memory and the presence and types of behavioural abnormalities were assessed based on interviews of patients and their close family members and a bedside examination. The correspondence between the cognitive 
domains and the neuropsychological measures are indicated in table 1.

\section{Stereotactic lesion localisation on MRI}

Coronal three-dimensional T1-weighted SPGR images (TR, $14 \mathrm{~ms}$; TE, $3 \mathrm{~ms}$; flip angle, $20^{\circ}$; resolution, $1.5 \times 0.86 \times 0.86 \mathrm{~mm}$ ) were obtained using a 1.5-T GE Signa Horizon system. The images were reconstructed into $1.0 \mathrm{~mm}$ isotropic transverse sections and then normalised to the Montreal Neurological Institute (MNI) T1 template using the affine transformation algorithm implemented in the SPM5 (http://www.fil.ion.ucl.ac. $\mathrm{uk} / \mathrm{spm} / \mathrm{software} / \mathrm{spm} 5 /$ ) software application. The lesions of each patient were traced on normalised images. The detailed localisation of the thalamic and adjacent structures involved was determined on transverse sections using an electronic version of the Schaltenbrand-Wahren $(\mathrm{S}-\mathrm{W})$ atlas. ${ }^{15}$ The correspondence of the transverse sections between the MNI-T1 template and the $\mathrm{S}-\mathrm{W}$ atlas was determined by scaling the z-axis with reference to the distance between the top of the thalamus and the AC-PC plane. In-plane two-dimensional linear coregistration was performed with reference to the intercommissural distance, interputaminal distance and contour of the thalamus.

\section{Positron emission tomography}

PET images were obtained from the six patients and six healthy subjects (75.2 \pm 9.0 years; six females) under resting conditions with their eyes closed using a Shimadzu Headtome-IV scanner. The regional cerebral blood flow ( $\mathrm{rCBF}$ ) was determined using a steady-state technique. The subjects continuously inhaled $\mathrm{O}_{2}$ at $500 \mathrm{MBq} / 200 \mathrm{ml} / \mathrm{min}$ during a 10 -minute scanning session. ${ }^{16}$ Arterial blood samples were collected to measure the blood radioactivity concentrations. Data were collected in $128 \times 128$ matrices, and the slice interval was $6.5 \mathrm{~mm}$ when the z-motion mode was used. ${ }^{17}$ The scan did not include the top of the frontal and parietal lobes and the inferior portion of the cerebellar hemispheres. Image preprocessing and statistical analyses were carried out using SPM5. The ventromedial prefrontal region was masked because of the presence of artefacts due to gas inhalation. The obtained images were reconstructed into $2 \mathrm{~mm}$ cubic voxels and then normalised to the SPM-PET template using affine transformation. The resultant images were smoothed with $12 \mathrm{~mm}$ full width at half maximum. Threshold masking was applied with a criterion of $80 \%$ of the mean global value. Proportional scaling was used to control the individual variation in the global CBF. Two-sample t-tests were used for a voxelwise group comparison between the patient and control groups. T-contrast maps were created with a height threshold of uncorrected $p<0.001$ and an extent threshold of 50 voxels $\left(400 \mathrm{~mm}^{3}\right)$. As the small number of the subjects could cause underestimation of group difference in rCBF, we additionally analysed the PET data on individual subject basis using regions of interests (ROIs). Twenty-one pairs

Table 1 Results of the neuropsychological tests

\begin{tabular}{|c|c|c|c|c|c|c|c|c|c|}
\hline \multirow{2}{*}{$\begin{array}{l}\text { Cognitive and } \\
\text { behavioural domains }\end{array}$} & \multirow[b]{2}{*}{ Tests } & & \multicolumn{6}{|c|}{ Patients } & \multirow{2}{*}{$\begin{array}{l}\text { Normative } \\
\text { data }\end{array}$} \\
\hline & & & 1 & 2 & 3 & 4 & 5 & 6 & \\
\hline \multirow[t]{3}{*}{ General intelligence } & \multicolumn{2}{|c|}{ MMSE (/30) } & 25 & 27 & 27 & $16^{*}$ & 24 & $22^{*}$ & $\geq 24$ \\
\hline & \multirow[t]{2}{*}{ WAIS-R ${ }^{7}$} & VIO & $68 *$ & $78^{*}$ & 88 & $65^{*}$ & $81^{*}$ & 89 & $\geq 85$ \\
\hline & & PIO & 85 & 106 & 93 & $66^{*}$ & 91 & 91 & $\geq 85$ \\
\hline \multirow[t]{5}{*}{ Episodic memory } & \multirow[t]{4}{*}{ WMS-R $^{8}$} & Verbal memory index & $<50^{*}$ & $64^{*}$ & $61^{*}$ & $<50^{*}$ & $50^{*}$ & $64^{*}$ & $\geq 85$ \\
\hline & & Visual memory index & $72^{*}$ & 93 & 118 & $68 *$ & 114 & 100 & $\geq 85$ \\
\hline & & Attention/concentration index & $66^{*}$ & $84^{*}$ & 94 & $55^{*}$ & $77^{*}$ & 97 & $\geq 85$ \\
\hline & & Delayed recall index & $<50^{*}$ & $<50^{*}$ & $69^{*}$ & $<50^{*}$ & $71^{*}$ & $83^{*}$ & $\geq 85$ \\
\hline & \multicolumn{2}{|c|}{ Retrograde amnesia } & $(-)$ & $(-)$ & $(-)$ & $(-)$ & $(-)$ & $(-)$ & \\
\hline \multirow{14}{*}{$\begin{array}{l}\text { Language/semantic } \\
\text { knowledge }\end{array}$} & \multirow[t]{7}{*}{$W A^{9}$} & $\mathrm{AO}$ & $69.2^{*}$ & $90.8^{*}$ & $86.4^{*}$ & $71^{*}$ & $83.6^{*}$ & $87.6^{*}$ & $97.7 \pm 3.0$ \\
\hline & & Spontaneous speech (/20) & $13^{*}$ & $17^{*}$ & $17^{*}$ & $12^{*}$ & $16^{*}$ & $16^{*}$ & $19.7 \pm 0.6$ \\
\hline & & Auditory comprehension (/10) & $7.2^{*}$ & 9.8 & $7.7^{*}$ & $7.2^{*}$ & $9 *$ & $9.5^{*}$ & $9.8 \pm 0.1$ \\
\hline & & Repetition (/10) & $8.9^{*}$ & 9.6 & 9.9 & 9.2 & 9.9 & 10 & $9.9 \pm 0.3$ \\
\hline & & Naming $(/ 10)$ & $5.5^{*}$ & 9 & $8.6^{*}$ & $7.1^{*}$ & $6.9^{*}$ & $8.3^{*}$ & $9.5 \pm 0.6$ \\
\hline & & Reading $(/ 10)$ & $6.7^{*}$ & 10 & 8.9 & $4.1^{*}$ & $7.2^{*}$ & $7.7^{*}$ & $9.5 \pm 0.8$ \\
\hline & & Writing (/10) & $6.4^{*}$ & 9.7 & 9.9 & $4^{*}$ & 9.1 & 8.9 & $9.6 \pm 1.0$ \\
\hline & \multicolumn{2}{|c|}{ Animal fluency (/min) } & $4^{*}$ & 10 & 9 & $4^{*}$ & $4^{*}$ & 12 & $11.8 \pm 4.4$ \\
\hline & \multicolumn{2}{|c|}{ Initial fluency (/min) } & $0^{*}$ & $3^{*}$ & $1^{*}$ & $1^{*}$ & $2^{*}$ & 7 & $6.8 \pm 3$ \\
\hline & \multicolumn{2}{|c|}{ Picture Naming $(/ 100)^{10}$} & $74^{*}$ & 97 & 84 & 66 & 86 & 89 & $98.2 \pm 2.3$ \\
\hline & \multirow[t]{4}{*}{ WAIS-R ${ }^{7}$} & Information SS & $6^{*}$ & $6^{*}$ & 10 & $5^{*}$ & $6^{*}$ & 8 & $\geq 7$ \\
\hline & & Vocabulary SS & $5^{*}$ & 7 & 7 & $5^{*}$ & $6^{*}$ & 9 & $\geq 7$ \\
\hline & & Comprehension SS & $2^{*}$ & 7 & $5^{*}$ & $2^{*}$ & 7 & $5^{*}$ & $\geq 7$ \\
\hline & & Similarities SS & $4^{*}$ & $5^{*}$ & 8 & $4^{*}$ & 8 & $6^{*}$ & $\geq 7$ \\
\hline \multirow{2}{*}{$\begin{array}{l}\text { Perceptual organisation/ } \\
\text { construction }\end{array}$} & \multirow[t]{2}{*}{ WAIS-R ${ }^{7}$} & Picture completion SS & 8 & 11 & 9 & $5^{*}$ & 8 & 9 & $\geq 7$ \\
\hline & & Block design SS & $5^{*}$ & 13 & 9 & $4^{*}$ & 12 & 11 & $\geq 7$ \\
\hline \multirow[t]{2}{*}{ Concept formation } & \multicolumn{2}{|c|}{$\operatorname{RCPM}(/ 36)^{12}$} & 25 & 30 & 23 & $14^{*}$ & 32 & 26 & $26.9 \pm 5.4$ \\
\hline & \multicolumn{2}{|c|}{ Weigl's colour-form sorting ${ }^{13}$} & $\swarrow$ & $x$ & レ & $x$ & レ & $\swarrow$ & \\
\hline Psychomotor speed & \multicolumn{2}{|c|}{ WAIS-R Digit symbol SS ${ }^{7}$} & $6^{*}$ & 8 & 9 & $4^{*}$ & 7 & 8 & $\geq 7$ \\
\hline \multirow[t]{3}{*}{ Executive/motor control } & \multicolumn{2}{|c|}{ Fist-edge-palm ${ }^{14}$} & $x$ & $x$ & $x$ & レ & $x$ & レ & \\
\hline & \multicolumn{2}{|c|}{ 2-1 tapping ${ }^{14}$} & $x$ & レ & レ & レ & $レ$ & レ & \\
\hline & \multicolumn{2}{|c|}{ Alternative pattern drawing ${ }^{14}$} & レ & レ & $\nu$ & 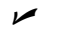 & レ & レ & \\
\hline Behaviour & \multicolumn{2}{|l|}{ Apathy } & $(++)$ & $(+)$ & $(+)$ & $(++)$ & $(+)$ & $(+)$ & \\
\hline
\end{tabular}

${ }^{*}$ Score below -1 SD of the normative data. ${ }^{8-12}$

$\checkmark$, passed; $x$, failed.

AQ, aphasia quotient; MMSE, Mini-Mental State Examination; PIQ, performance intelligence quotient; RCPM, Raven's coloured progressive matrices; SS, scaled score; VIQ, verbal intelligence quotient; WAB, Western Aphasia Battery; WAIS-R, Wechsler Adult Intelligence Scale-Revised; WMS-R, Wechsler Memory Scale-Revised. 
of $8 \mathrm{~mm}$ spherical ROIs of each hemisphere were determined on the mean normalised PET image of the 12 subjects using the MarsBar toolbox (http://marsbar.sourceforge.net/). Left/right asymmetry indices (calculated as (mean voxel value of left ROI)/ (mean voxel value of right ROI)) of each patient were compared to $95 \%$ CIs of that obtained from the six control subjects. ${ }^{18} 19$

\section{RESULTS}

\section{Neuropsychology and behaviour}

The results of the neuropsychological tests and behavioural observations are summarised in table 1.

\section{General intelligence}

The verbal intelligence quotient (VIO) of the WAIS-R was less than 85 ( -1 SD of the normative mean) in four of the six patients, whereas the performance IO was within the normal range in all patients except Patient 4

\section{Episodic memory}

All patients showed impairments in the verbal memory index (MI) of the WMS-R (<85, $-1 \mathrm{SD})$. Their verbal MI was disproportionately lower than their VIO in the WAIS-R (verbal MI $\mathrm{VIO} \geq 10)^{8}$. Retrograde memory was preserved in all patients.

\section{Language/semantic knowledge}

The spontaneous speech score was impaired in all patients due to poor information content and word-finding difficulties. Semantic paraphasias were occasionally observed in some patients. Articulatory errors and phonological paraphasias were not observed. All patients excluding Patient 2 showed anomia in the naming subtest of the Western Aphasia Battery and/or in the picture naming test of 100 words. Apparent reading and writing disabilities were observed in two patients (Patients 1 and 4). All the patients were impaired $(<7)$ in at least one of the subtests of the WAIS-R: Information, Vocabulary, Comprehension and Similarities.

\section{Perceptual organisation/construction}

Five of the six patients performed at normal levels on the Picture Completion and Block Design subtests of the WAIS-R.

Executive function (concept formation, psychomotor speed and executive/motor control)

Although all patients excluding Patient 6 were impaired in at least one of the executive function tests, no consistent tendency in the test categories showing impairment was found in the patient group.

\section{Behaviour}

Apathy was observed in all patients. Lack of spontaneity, reduced emotional response and psychomotor retardation were observed in Patients 1 and 4. In the other four patients, their apathy was milder and consisted only of lack of spontaneity. Other behavioural alterations that have been associated with frontal lobe damage, such as disinhibition, irritability and repetitive behaviours, were not observed.

\section{Stereotactic lesion localisation}

The results are shown in figure 1 and table 2. Designations of the thalamic nuclei were according to Hirai and Jones. ${ }^{20}$ The ventral anterior proper (VA proper; also referred to as the parvocellular VA or just the VA), magnocellular ventral anterior nucleus (VAmc), ventral lateral anterior (VLa), ventral lateral posterior (VLp), reticular (R) nuclei and mammillothalamic tract (MTT)

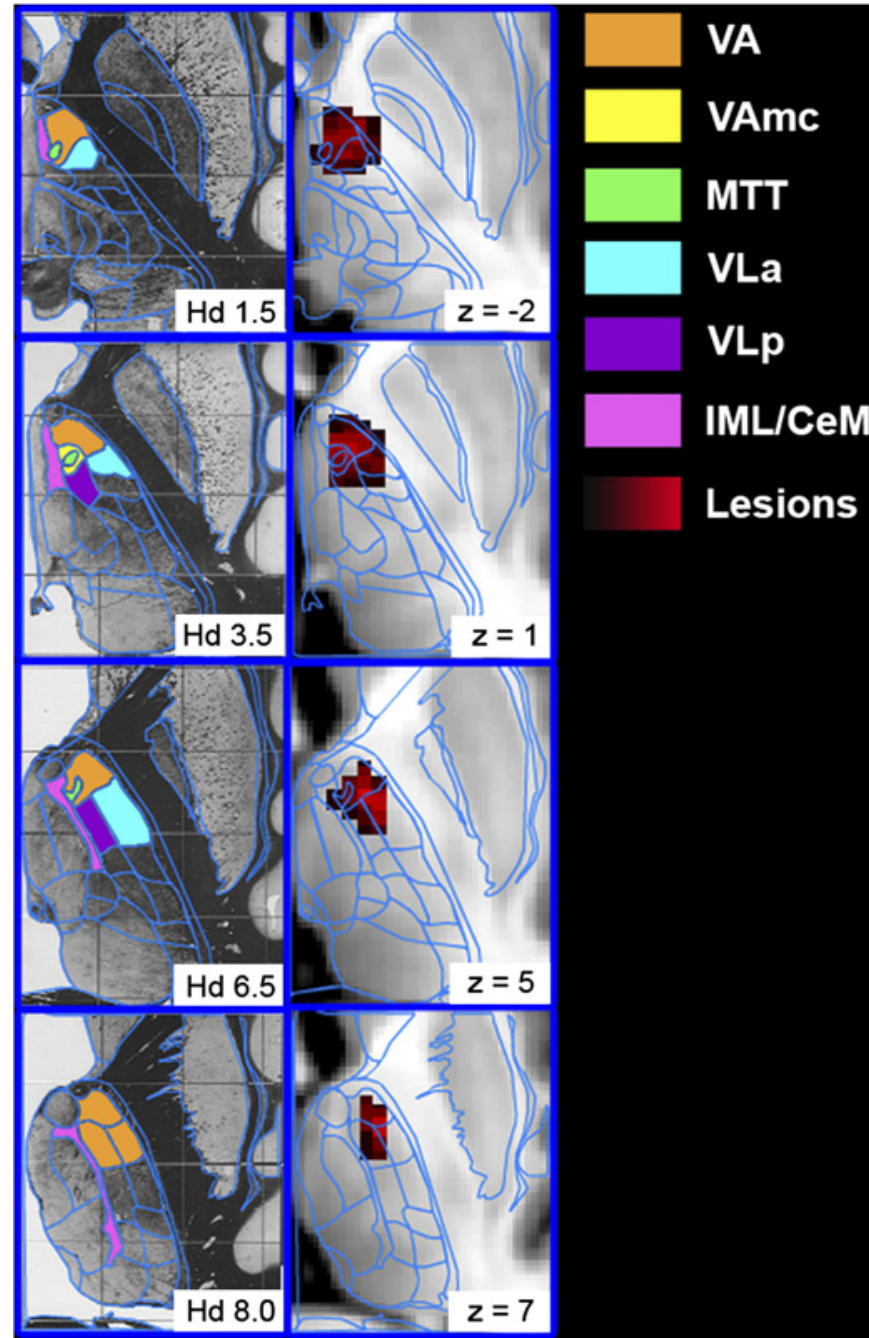

Figure 1 Transverse images from the Schaltenbrand-Wahren (S-W) atlas are shown in the left column. The structures involved in left anterior thalamic infarction are coloured. Images showing lesions (red) superimposed on the Montreal Neurological Institute (MNI) template are indicated in the right column. The voxels that overlapped in more patients are coloured in brighter red. CeM, central medial nucleus; IML, internal medullary lamina; MTT, mammillothalamic tract; VA, ventral anterior nucleus proper; VAmc, magnocellular ventral anterior nucleus; VLa, ventral lateral anterior nucleus; VLp, ventral lateral posterior nucleus.

were involved in all patients. The anterior nuclei (AN) were preserved in all patients. The mediodorsal nucleus (MD) was involved only in Patient 4. The internal medullary lamina (IML)/ central medial nucleus (CeM) was affected in three patients with lesions that were located medially (Patients 2, 4 and 5). The genu of the internal capsule (ICg) was damaged at the site ventral to the thalamus in Patients 3, 4 and 5.

\section{Positron emission tomography}

A voxelwise group comparison revealed significant $\mathrm{rCBF}$ reductions in the anterior temporal lobe (ATL), thalamus, orbital frontal lobe (OFL) and middle frontal gyrus (MFG) of the left hemisphere in the patients with LATI compared to the control subjects (figure 2). A relative increase in $\mathrm{rCBF}$ was detected in the right precuneus and right lingual gyrus. An ROI analysis showed decreased left/right asymmetry index (lower rCBF in the left side compared to the right side) in the anterior cingulate gyrus, inferior temporal gyrus, inferior parietal lobule, calcarine 
Table 2 The thalamic and adjacent regions affected in the patients

\begin{tabular}{|c|c|c|c|c|c|c|c|c|}
\hline \multicolumn{2}{|l|}{ Thalamic regions } & \multicolumn{6}{|c|}{ Patient No. } & \multirow{2}{*}{$\begin{array}{l}\text { No. of } \\
\text { patients }\end{array}$} \\
\hline Hirai and Jones' & Hassler's & 1 & 2 & 3 & 4 & 5 & 6 & \\
\hline VA proper & Lpo & $(+)$ & $(+)$ & $(+)$ & $(+)$ & $(+)$ & $(+)$ & 6 \\
\hline VAmc & Lpo.mc & $(+)$ & $(+)$ & $(+)$ & $(+)$ & $(+)$ & $(+)$ & 6 \\
\hline \multirow[t]{4}{*}{ VLa } & Zo & $(+)$ & $(+)$ & $(+)$ & $(+)$ & $(+)$ & $(+)$ & 6 \\
\hline & Voa & $(+)$ & $(+)$ & $(+)$ & $(+)$ & $(+)$ & $(+)$ & \\
\hline & Vop & $(-)$ & $(-)$ & $(-)$ & $(-)$ & $(+)$ & $(-)$ & \\
\hline & Doe & $(+)$ & $(+)$ & $(+)$ & $(+)$ & $(+)$ & $(+)$ & \\
\hline \multirow[t]{2}{*}{ VLp } & Voi & $(+)$ & $(+)$ & $1+1$ & $(+)$ & $(+)$ & $1+1$ & 6 \\
\hline & Doi & $(+)$ & $(+)$ & $(+)$ & $(+)$ & $(+)$ & $(+)$ & \\
\hline VM & Vom & $(-)$ & $(+)$ & $(-)$ & $(-)$ & $(-)$ & $(-)$ & 1 \\
\hline MD & Mfa & $(-)$ & $(-)$ & $(-)$ & $(+)$ & $(-)$ & $(-)$ & 1 \\
\hline IML/CeM & Lam & $(-)$ & $(+)$ & $(-)$ & $(+)$ & $(+)$ & $(-)$ & 3 \\
\hline $\mathrm{R}$ & & $(+)$ & $(+)$ & $(+)$ & $(+)$ & $(+)$ & $(+)$ & 6 \\
\hline MTT & & $(+)$ & $(+)$ & $(+)$ & $(+)$ & $1+1$ & $(+)$ & 6 \\
\hline $\mathrm{ICg}$ & & $(-)$ & $(-)$ & $(-)$ & $(+)$ & $(+)$ & $(+)$ & 3 \\
\hline H & & $(-)$ & $(-)$ & $(-)$ & $(+)$ & $(+)$ & $(-)$ & 2 \\
\hline STN & & $(-)$ & $(-)$ & $(-)$ & $(+)$ & $(-)$ & $(-)$ & 1 \\
\hline
\end{tabular}

The nomenclature for the thalamic nuclei is according to Hirai and Jones and Hassler. $\mathrm{CeM}$, central medial nucleus; $\mathrm{H}$, fields of Forel; $\mathrm{ICg}$, genu of the internal capsule; IML, internal medullary lamina; MD, mediodorsal nucleus; MTT, mammillothalamic tract; $\mathrm{R}$, reticular nucleus; STN, subthalamic nucleus; VA, ventral anterior nucleus; VAmc, magnocellular ventral anterior nucleus; VLa, ventral lateral anterior nucleus; VLp, ventral lateral posterior nucleus; VM, ventral medial nucleus.

gyrus and cuneus in addition to the ATL, thalamus, OFL, and MFG. Increased left/right asymmetry index was observed in the precuneus (table 3 ).

\section{DISCUSSION}

\section{Clinical features of LATI}

In agreement with previous reports of LATI, the symptoms of our patients were characterised primarily by memory impairment, language disturbances and apathy. ${ }^{1} \begin{array}{llll}3 & 4 & 21 & \text { Although }\end{array}$ previous studies of acute LATI have reported a perseverative behaviour (palipsychism) and mild sensorimotor deficits, ${ }^{21}$ we did not observe these symptoms.

The memory impairment was restricted to the anterograde domain and dominant in the verbal materials. Although the concomitant deficits in language, attention and executive function may partly explain the memory impairment observed in our patients, the dissociation between the verbal MI of the WMS-R and the VIO of the WAIS-R suggested that our patients had deficits in the memory function itself. A hypothesis has been recently proposed that selective or predominant memory impairment of verbal materials in left temporal lobe pathology arises from concomitant deficits in semantic processing and protosemantic components of episodic memory. ${ }^{22}$ The same perspective may be applicable to material-specific memory impairment in thalamic damage.

The language disturbances in our patients were characterised by word-finding difficulty and anomia. The articulation and phonological aspects were well preserved. Anomia and poor performance in the naming tests and the Information, Vocabulary, Comprehension and Similarities subtests of the WAIS-R suggested that the lexical-semantic impairment was the core deficit responsible for their language symptoms. ${ }^{4}$ This interpretation is supported by previous reports investigating a variety of lexical-semantic deficits, including category-specific anomia, proper name anomia and degraded knowledge of object use, in patients with LATI. ${ }^{5} 23-25$

\section{Cortical diaschisis in LATI}

Using CBF diaschisis, we demonstrated that the connections of the thalamus with the dorsolateral, medial and orbital frontal lobes, the ATL, the inferior parietal lobule and the occipital lobe were disrupted in LATI. Compared to patients with paramedian thalamic infarction (PTI), ${ }^{26}$ the extent of hypoperfusion regions in our patients was relatively restricted. This difference in PET findings is well correspondent with that in clinical manifestations; patients with PTI develop more severe behavioural symptoms compared with those that had anterior thalamic infarction (ATI), for example, coma, akinetic mutism and confusion. ${ }^{3} 26$ The involvement of the intralaminar nuclei, which project broadly to the cerebral cortex, ${ }^{20}$ and/or their projecting fibres probably causes extensive cortical dysfunction in PTI. ${ }^{3}{ }^{4}$ A previous single-case PET study of LATI reported restricted $\mathrm{rCBF}$ reductions in the ipsilateral amygdala and posterior cingulate cortex. ${ }^{27}$ The disagreement between this and our studies is probably related to difference in affected thalamic structures and in neuroimaging analysis.

\section{Neuroanatomical basis of memory impairment}

The neural circuit that arises from the hippocampus via the fornix, mammillary body (MB), MTT, AN and posterior cingulate cortex and then projects back to the hippocampus is known
Figure 2 Results of the voxelwise group comparison of positron emission tomography. Regions with regional cerebral blood flow (rCBF) reduction are superimposed on the mean normalised MRls of the patients. The table indicates relative decrease and increase in rCBF in patients with left anterior thalamic infarction compared to controls. The height and extent thresholds were $\mathrm{p}<0.001$ uncorrected and $400 \mathrm{~mm}^{3}$, respectively. LATI, left anterior thalamic infarct.

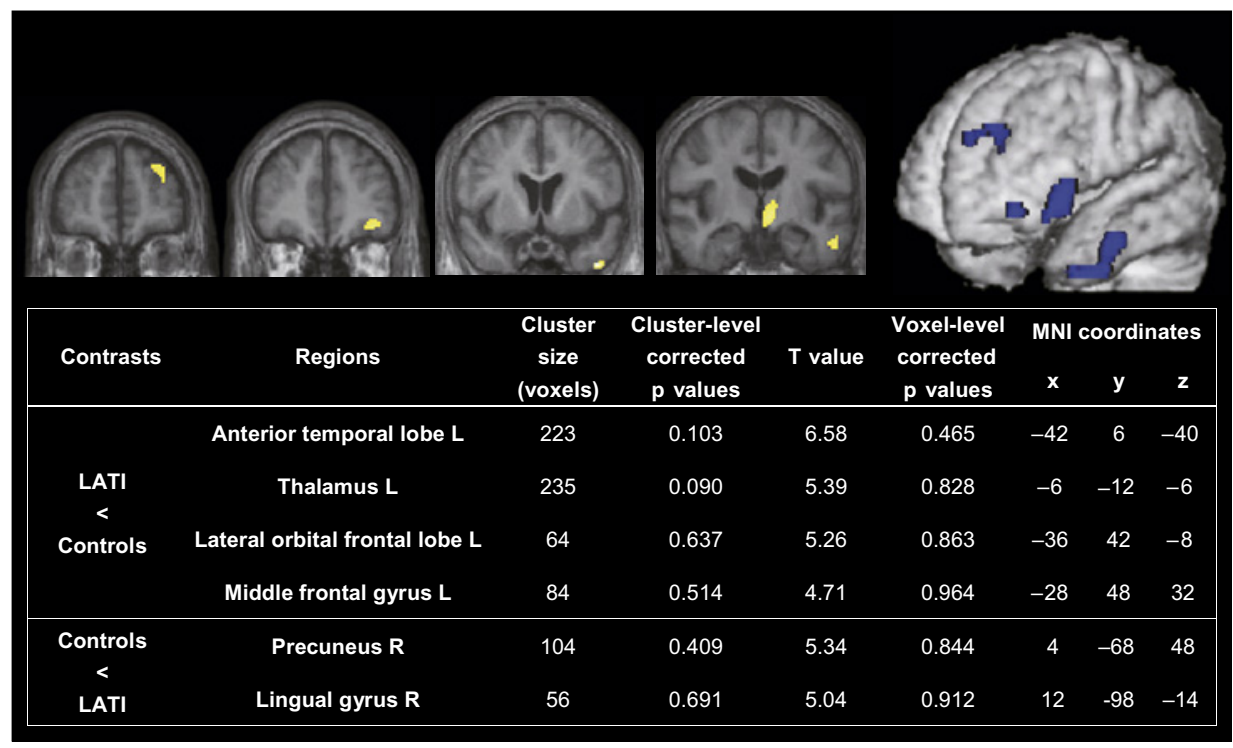


Table 3 Left/right asymmetry indices obtained from the regions of interest- (ROI) based positron emission tomography analysis

\begin{tabular}{|c|c|c|c|c|c|c|c|c|}
\hline \multirow[b]{3}{*}{ Inferior frontal } & \multicolumn{6}{|c|}{ Patients } & \multirow{2}{*}{\multicolumn{2}{|c|}{$\begin{array}{l}\text { Controls } \\
(\mathrm{n}=6) \\
95 \% \mathrm{CI}\end{array}$}} \\
\hline & \multirow{2}{*}{$\begin{array}{l}1 \\
0.79\end{array}$} & \multirow{2}{*}{$\begin{array}{l}2 \\
1.03\end{array}$} & \multirow{2}{*}{$\begin{array}{l}3 \\
0.91\end{array}$} & \multirow{2}{*}{$\begin{array}{l}4 \\
0.82\end{array}$} & \multirow{2}{*}{$\begin{array}{l}5 \\
0.71\end{array}$} & \multirow{2}{*}{$\begin{array}{l}6 \\
0.88\end{array}$} & & \\
\hline & & & & & & & 0.84 & 1.37 \\
\hline Middle frontal & 0.80 & 0.93 & 0.93 & 1.01 & 0.76 & 0.82 & 0.86 & 1.25 \\
\hline Frontal operculum & 1.08 & 1.13 & 1.01 & 1.03 & 0.88 & 0.85 & 0.86 & 1.29 \\
\hline Lateral orbital frontal* & 0.80 & 0.92 & 1.14 & 0.90 & 0.69 & 0.85 & 0.97 & 1.20 \\
\hline Anterior cingulate ${ }^{*}$ & 0.78 & 0.87 & 0.94 & 0.99 & 0.80 & 0.79 & 0.95 & 1.18 \\
\hline Central & 1.16 & 0.97 & 1.04 & 0.85 & 0.77 & 0.80 & 0.87 & 1.11 \\
\hline Temporal pole* & 0.86 & 0.86 & 0.87 & 0.92 & 0.80 & 0.89 & 0.95 & 1.17 \\
\hline Inferior temporal* & 1.15 & 0.92 & 1.02 & 0.94 & 0.93 & 0.81 & 0.95 & 1.21 \\
\hline Middle temporal & 1.05 & 0.86 & 0.87 & 1.03 & 1.07 & 1.02 & 0.85 & 1.05 \\
\hline Superior temporal & 1.05 & 1.20 & 1.14 & 0.77 & 1.04 & 0.89 & 0.87 & 1.20 \\
\hline Medial temporal & 1.36 & 1.00 & 1.08 & 1.24 & 0.83 & 0.90 & 0.89 & 1.05 \\
\hline Inferior parietal ${ }^{*}$ & 0.84 & 0.88 & 1.17 & 0.89 & 0.67 & 0.87 & 1.00 & 1.27 \\
\hline Posterior cingulated & 0.94 & 1.04 & 1.03 & 1.00 & 1.41 & 0.93 & 0.86 & 1.10 \\
\hline Precuneus $†$ & 1.17 & 1.18 & 1.17 & 0.95 & 1.16 & 0.84 & 0.91 & 1.08 \\
\hline Cuneus* & 0.82 & 0.85 & 1.12 & 0.94 & 0.93 & 1.07 & 1.05 & 1.25 \\
\hline Calcarine* & 1.11 & 0.79 & 0.81 & 0.87 & 0.85 & 0.82 & 0.91 & 1.16 \\
\hline Lingual & 1.24 & 1.14 & 0.96 & 0.94 & 1.12 & 0.96 & 0.88 & 1.38 \\
\hline Fusiform & 0.95 & 0.98 & 0.93 & 1.02 & 0.97 & 0.95 & 0.95 & 1.09 \\
\hline Anterior striatum & 1.07 & 1.22 & 0.90 & 0.82 & 0.85 & 0.98 & 0.83 & 1.13 \\
\hline Posterior striatum & 1.18 & 1.19 & 1.14 & 0.94 & 0.45 & 0.94 & 0.92 & 1.21 \\
\hline Thalamus* & 0.66 & 0.80 & 0.86 & 0.77 & 0.57 & 0.75 & 0.92 & 1.19 \\
\hline
\end{tabular}

as the Papez or Delay-Brion circuit. This circuit has long been considered to play a central role in memory. In addition, the significance of the rhinal/parahippocampal-MD-prefrontal network has been recently recognised. ${ }^{28}$ Because the $\mathrm{AN}$ and $\mathrm{MD}$ are spared in the majority of patients with ATI, ${ }^{329}$ the disconnection of these neural networks at the intrathalamic white matter structures, namely the MTT and IML, have been considered critical in memory impairment in ATI. ${ }^{29-31}$ In the present case series, the MTT was consistently involved, whereas the IML was affected only in half of the patients, suggesting the significance of Papez circuit disruption. In addition, we propose a possible role of lesions in the VA region, which is penetrated anteroposteriorly by the inferior thalamic peduncle, the bundle carrying the fibres from the rhinal/parahippocampal cortex to the $\mathrm{MD}{ }^{20}$ In contrast with this view, however, our PET analysis did not detect diaschisis in the medial temporal lobe and other components of the Papez circuit. Two possible factors may be associated with this negative result: diaschisis is presumably hard to be observed in the disruption of polysynaptic connections, ${ }^{26}$ for example, the connection between the MTT and the posterior cingulate cortex via the $\mathrm{AN}$; $\mathrm{rCBF}$ reduction is an insensitive measure to detect medial temporal dysfunction. ${ }^{32} 33$ This issue should be addressed using different neuroimaging modalities, such as fluorodeoxyglucose PET and diffusion tensor tractography, in future studies.

\section{Neuroanatomical basis of language disturbance}

It is noteworthy that diaschisis was observed in the ATL, which is a region that is putatively associated with the integration of lexical and semantic information. ${ }^{34} 35$ Both LATI and left ATL damage have been linked to semantic-lexical deficits, including category-specific anomia and proper name anomia. ${ }^{24} 3637$ This symptomatic similarity suggests the presence of functional relationships between these two regions. Connectional anatomical studies in monkeys have shown anatomical connections between the VAmc, a thalamic structure consistently involved in ATI, and the anterior temporal neocortex. ${ }^{38}$ We propose that thalamo-anterior temporal disconnection plays a significant role in the language disturbances observed in LATI. Some investigators have speculated that the disruption of the intralaminar nuclei-inferior thalamic peduncle-prefrontal system is critical in the language disturbances observed in LATI. $^{39}$ Although the IML was involved only in half of our patients, diaschisis in the dorsolateral prefrontal cortices was demonstrated in our PET analysis. The thalamo-dorsolateral prefrontal disconnection may also be related to the linguistic symptoms.

Behavioural symptoms and their relevance to cortical diaschisis Apathy is the most common behavioural feature in the current and previously reported cases of LATI. ${ }^{321}$ Although apathy can result from lesions in various locations, ${ }^{40}$ it has been particularly associated with anterior cingulate damage. Consistently, rCBF reduction in the left anterior cingulated gyrus was observed in our patients. In the original formulation of the frontal-subcortical circuits, ${ }^{2}$ disinhibited behaviour is linked to disruption of the orbitofrontal circuit. However, none of our patients developed such kind of behavioural alteration in spite of diaschisis in the OFL. Previous studies have suggested that disinhibition syndrome occurs after right-lateralised lesions. ${ }^{41}{ }^{42}$ The lack of disinhibited behaviour in our patients is presumably associated with the laterality of the lesions.

\section{Limitations of the study}

The first limitation of the study is the small sample size. Age, disease duration, subclinical neurodegenerative pathologies and individual differences in functional lateralisation among others, may have had a large effect on the clinical presentation and neuroimaging results. Clinical-PET correlation analyses were unavailable also due to the small number of subjects. Although much larger sample sizes are needed to overcome these problems, it would be quite difficult to recruit a sufficient number of subjects from a single institution due to the rarity of isolated ATI. A meta-analysis of studies that have performed detailed neuroimaging investigations would be valuable. Also, the probable selection bias on the neuropsychological and behavioural findings should be noted. Since we performed the study in a dementia department, only patients with cognitive problems mimicking dementia may have been referred to us. Lack of sensorimotor deficits and perseverative behaviours ${ }^{21}$ and relatively long-lasting cognitive impairment may be associated with such kind of bias. Finally, as it took a long time, over 7 years, to recruit the patients, we failed to update the neuropsychological tests. Therefore, we could not incorporate new cognitive theories, such as the recollection/familiarity components of episodic memory. 43

There are a number of methodological limitations to our neuroimaging investigations. The precision of lesion localisation on MRI is limited by image distortion due to magnetic field inhomogeneity, inaccuracy of spatial normalisation and image co-registration, difficulty in defining exact lesion boundaries and so forth. In the PET analyses, the proportional scaling probably led to underestimation of the spatial extent and strength of hypoperfusion and to spurious hyperperfusion. The ROI-based left/right asymmetry analysis is unable to detect bilateral rCBF changes. ${ }^{19}$ Lastly, inhalation artefacts precluded the evaluation of the ventromedial frontal regions, which are reported to have dense interconnections with the thalamic structures. ${ }^{20} 44$ 
Funding This work was supported by Grants-in-Aid for dementia research from the MHLW Japan (22800).

Competing interests None.

Ethics approval This study was conducted with the approval of the Hyogo Institute for Aging Brain and Cognitive Disorders.

Provenance and peer review Not commissioned; externally peer reviewed.

\section{REFERENCES}

1. Carrera $\mathbf{E}$, Bogousslavsky J. The thalamus and behavior: effects of anatomically distinct strokes. Neurology 2006;66:1817-23.

2. Cummings JL. Frontal-subcortical circuits and human behavior. Arch Neurol 1993;50:873-80.

3. Schmahmann JD. Vascular syndromes of the thalamus. Stroke 2003:34:2264-78.

4. Mori E, Ishii K, Hashimoto $\mathrm{M}$, et al. Role of functional brain imaging in the evaluation of vascular dementia. Alzheimer disease and associated disorders 1999;13(Suppl 3): S91-101.

5. Mori E, Yamadori A, Mitani Y. Left thalamic infarction and disturbance of verbal memory: a clinicoanatomical study with a new method of computed tomographic stereotaxic lesion localization. Ann Neurol 1986:20:671-6.

6. Mori E, Mitani Y, Yamadori A. Usefulness of a Japanese version of the Mini-Mental State Test in neurological patients. Japanese Journal of Neuropsychology 1985;1:82-90.

7. Shinagawa F, Kobayashi S, Fujita K, et al. Japanese Wechsler Adult Intelligence Scale-Revised. Tokyo: Nihon Bunka Kagakusha, 1990.

8. Sugishita M. Japanese Wechsler Memory Scale-Revised. Tokyo: Nihon Bunka Kagakusha, 2000.

9. Sugishita M. The Japanese Edition of the Western Aphasia Battery. Tokyo: Igaku Shoin, 1986

10. Imamura T, Takatsuki Y, Fujimori M, et al. Age at onset and language disturbances in Alzheimer's disease. Neuropsychologia 1998:36:945-9.

11. Ito $\mathbf{E}$, Hatta $T$, Ito $Y$, et al. Performance of verbal fluency tasks in Japanese healthy adults. Jpn J Neuropsychol 2004:20:254-63.

12. Sugishita M, Yamazaki K. Japanese Raven's Coloured Progressive Matrices. Tokyo: Nihon Bunka Kagakusha, 1993

13. Weigl E. On the psychology of so-called processes of abstraction. Journal of Normal and Social Psychology 1941;36:3-33.

14. Lezak MD. Neuropsychological Assessment. New York: Oxford University Press, 1995.

15. Nowinski WL, Thirunavuukarasuu A, Benarbid AL. The Cerefy Clinical Brain Atlas 2nd edn. New York: Thieme, 2005

16. Frackowiak RS, Lenzi GL, Jones $\mathrm{T}$, et al. Quantitative measurement of regional cerebral blood flow and oxygen metabolism in man using 150 and positron emission tomography: theory, procedure, and normal values. J Comput Assist Tomogr 1980;4:727-36

17. Ishii K, Sasaki M, Kitagaki $H$, et al. Regional difference in cerebral blood flow and oxidative metabolism in human cortex. J Nucl Med 1996:37:1086-8.

18. Baron JC, D'Antona R, Pantano P, et al. Effects of thalamic stroke on energy metabolism of the cerebral cortex. A positron tomography study in man. Brain 1986;109:1243-59.

19. Baron JC, Levasseur M, Mazoyer B, et al. Thalamocortical diaschisis: positron emission tomography in humans. J Neurol Neurosurg Psychiatry 1992;55:935-42.
20. Jones EG. The Thalamus. 2nd edn. Cambridge, New York: Cambridge University Press, 2007

21. Ghika-Schmid F, Bogousslavsky J. The acute behavioral syndrome of anterior thalamic infarction: a prospective study of 12 cases. Ann Neurol 2000:48:220-7.

22. Saling MM. Verbal memory in mesial temporal lobe epilepsy: beyond material specificity. Brain 2009:132:570-82.

23. Cohen L, Bolgert F, Timsit $S$, et al. Anomia for proper names after left thalamic infarct. J Neurol Neurosurg Psychiatry 1994;57:1283-4.

24. Levin N, Ben-Hur T, Biran I, et al. Category specific dysnomia after thalamic infarction: a case-control study. Neuropsychologia 2005;43:1385-90.

25. Rai M, Okazaki Y, Inoue N, et al. Object use impairment associated with left anterior thalamic infarction. Eur Neurol 2004:52:252-3.

26. Levasseur M, Baron JC, Sette G, et al. Brain energy metabolism in bilateral paramedian thalamic infarcts. A positron emission tomography study. Brain 1992:115:795-807.

27. Clarke S, Assal G, Bogousslavsky J, et al. Pure amnesia after unilateral left polar thalamic infarct: topographic and sequential neuropsychological and metabolic (PET) correlations. J Neurol Neurosurg Psychiatry 1994;57:27-34.

28. Aggleton JP. EPS Mid-Career Award 2006. Understanding anterograde amnesia: disconnections and hidden lesions. O J Exp Psychol (Colchester) 2008:61:1441-71.

29. Van der Werf YD, Witter MP, Uylings HB, et al. Neuropsychology of infarctions in the thalamus: a review. Neuropsychologia 2000;38:613-27.

30. Graff-Radford NR, Tranel D, Van Hoesen GW, et al. Diencephalic amnesia. Brain 1990;113:1-25.

31. von Cramon DY, Hebel N, Schuri U. A contribution to the anatomical basis of thalamic amnesia. Brain 1985:108.993-1008.

32. Dai W, Lopez OL, Carmichael OT, et al. Mild cognitive impairment and Alzheimer disease: patterns of altered cerebral blood flow at MR imaging. Radiology 2009;250:856-66.

33. Guedj E, Barbeau EJ, Didic M, et al. Effects of medial temporal lobe degeneration on brain perfusion in amnestic $\mathrm{MCl}$ of $\mathrm{AD}$ type: deafferentation and functional compensation? Eur J Nucl Med Mol Imaging 2009;36:1101-12.

34. Patterson K, Nestor PJ, Rogers TT. Where do you know what you know? The representation of semantic knowledge in the human brain. Nature reviews 2007:8:976-87.

35. Simmons WK, Martin A. The anterior temporal lobes and the functional architecture of semantic memory. J Int Neuropsychol Soc 2009:15:645-9.

36. Gainotti G. What the locus of brain lesion tells us about the nature of the cognitive defect underlying category-specific disorders: a review. Cortex 2000:36:539-59.

37. Yasuda K, Nakamura T, Beckman B. Brain processing of proper names. Aphasiology 2000;14:1067-89.

38. Middleton FA, Strick PL. The temporal lobe is a target of output from the basal ganglia. Proc Natl Acad Sci U S A 1996;93:8683-7.

39. Nadeau SE, Crosson B. Subcortical aphasia. Brain Lang 1997;58:355-402; discussion 18-23.

40. Marin RS, Wilkosz PA. Disorders of diminished motivation. J Head Trauma Rehabil 2005:20:377-88.

41. Rosen HJ, Allison SC, Schauer GF, et al. Neuroanatomical correlates of behavioural disorders in dementia. Brain 2005;128:2612-25

42. Starkstein SE, Robinson RG. Mechanism of disinhibition after brain lesions. J Nerv Ment Dis 1997; 185:108-14

43. Aggleton JP, Brown MW. Episodic memory, amnesia, and the hippocampal-anterior thalamic axis. Behav Brain Sci 1999;22:425-44; discussion 44-89.

44. Schmahmann JD, Pandya DN. Fiber Pathways of the Brain. Oxford, New York: Oxford University Press, 2006. 